\title{
Existing data sources for clinical epidemiology: Aarhus University Prescription Database
}

\author{
This article was published in the following Dove Press journal: \\ Clinical Epidemiology \\ I December 2010 \\ Number of times this article has been viewed
}

\section{Vera Ehrenstein \\ Sussie Antonsen \\ Lars Pedersen}

Department of Clinical Epidemiology, Aarhus University Hospital, Denmark
Correspondence:Vera Ehrenstein Department of Clinical Epidemiology, Aarhus University Hospital, Olof Palmes Allé 43-45, 8200 Aarhus N, Denmark $\mathrm{Tel}+4589424800$

Fax +45 8942480 I

Email ve@dce.au.dk
Abstract: Population-based prescription databases in Nordic countries have become a mainstay of epidemiologic research. Denmark has both national and regional population-based prescription databases. Aarhus University Prescription Database collects data on reimbursed medications dispensed at all community pharmacies of the North Denmark Region and the Central Denmark Region. The regions have a combined population of 1.8 million inhabitants, or one-third of the Danish population. Denmark's primary health care sector, which includes general practitioners, specialists, and dentists, generates about $96 \%$ of the prescription sales, most of which are reimbursable and are dispensed by the community pharmacies. The Aarhus University Prescription Database combines the region's pharmacy records in a single database, maintained and updated for research purposes. Each dispensation record contains patient-, drug-, and prescriber-related data. Dispensation records retain patients' universal personal identifier, which allows for individual-level linkage to all Danish registries and medical databases. The linked data have many applications in clinical epidemiology, including drug utilization studies, safety monitoring, etiologic research, and validation studies.

Keywords: epidemiology, prescriptions, registry-based research

Prescription registries in Nordic countries have become a mainstay of epidemiologic research. ${ }^{1,2}$ Since its inception, in 1994, The Danish Registry of Medicinal Products Statistics has collected records on sales of all medicinal products nationwide, including individual-level data on outpatient dispensations and aggregate data on in-hospital dispensations. ${ }^{1}$ These data are accessible for research purposes via a database copy in Statistics Denmark. Advantages of the Registry of Medicinal Products Statistics for epidemiologic research include availability of records since the mid-1990s, the possibility to achieve large sample size due to nationwide coverage, and inclusion of all prescription medications regardless of reimbursement status. Important drawbacks of the Registry of Medicinal Products Statistics are potentially high costs associated with data acquisition from Statistics Denmark and restrictions on the export of raw data outside Statistics Denmark. ${ }^{2}$ These are barriers to potentially more widespread use of the Danish National Prescription Registry for epidemiologic research. ${ }^{1-3}$

In addition to the Registry of Medicinal Products Statistics, Denmark has two regional databases maintained for research purposes. One database is hosted by the University of Southern Denmark (the Odense University Pharmacoepidemiological Database), and the other database is hosted by Aarhus University (the Aarhus University Prescription Database). The regional databases are more easily accessible for data linkage and authorized export than the Registry of Medicinal Products Statistics, while 
containing largely overlapping information. The regional databases thus represent an alternative source of populationbased prescription data. Recently, Furu et al provided a brief comparative overview of all Nordic prescription databases. ${ }^{1}$ The early description of Aarhus University Prescription Database was published in $1996,{ }^{4}$ before Denmark's municipal reform of 2007. ${ }^{5}$ This paper aims to provide a detailed and up-to-date description of the Aarhus University Prescription Database as a resource for epidemiologic research. Other names of this database used in published literature include "Pharmacoepidemiologic Prescription Database of North Jutland"6 and "Prescription Databases of the North Denmark and Central Denmark Regions". ${ }^{1}$

\section{Health care and prescribed medicine in Denmark}

Denmark is a welfare state, with tax-financed universal access to health services. ${ }^{7}$ Except for emergencies, patients' initial contact with the health care system is through their general practitioners, who provide referrals to hospitals and specialists as necessary. The primary health care sector is represented by about 4100 general practitioners, 1200 specialists, and 4600 dentists, as well as physiotherapists, chiropractors, and home nurses. There are about 300 community pharmacies. $^{7}$ Prescriptions originating from the primary health care sector account for approximately $96 \%$ of the total volume of medicinal product sales in Denmark. ${ }^{8}$

Most prescription medications in Denmark are eligible for full or partial general reimbursement by the National Health Service (Sygesikringer). Adults (persons aged 18 years or older) become eligible for reimbursement after exceeding 850 Danish kroner ( 114 Euro, 151 US dollars) in annual out-of-pocket expenditure for prescription medicine; children (persons under age 18 years) are exempt from the out-of-pocket expense requirement. ${ }^{9}$ Drugs ineligible for general reimbursement include sedatives, hypnotics, oral contraceptives, and over-the-counter (OTC) medicine. Conditional reimbursement, however, may be granted for prescription-only and OTC medicines, if they are prescribed for chronic conditions or to certain patient groups (eg, senior citizens). ${ }^{10}$ The Danish Medicines Agency (Laegemiddelstyrelsen, www.dkma.dk) regularly posts on its website updated rosters of generally and conditionally reimbursable medicines. ${ }^{10}$ Changes in reimbursement policies have been described, since 2005, on a dedicated website (http://www.dkma.dk/1024/visUKLSArtikel. asp?artikelID = 6301) ${ }^{11}$

\section{Population and period covered by the Aarhus University Prescription Database}

Aarhus University Prescription Database covers the population of the Central Denmark Region and the North Denmark Region. These are two of the five Danish regions, with a combined population of 1.8 million inhabitants, or about one-third of the total Danish population (Table 1, Figure 1). Following the municipal reform, which went into effect on 1 January 2007, regions replaced counties as administrative units in Denmark. As a result, the Central Denmark Region and the North Denmark Region now encompass four former counties: Aarhus, North Jutland, Ringkjøbing, and Viborg, as well as seven municipalities of the former Vejle county (Table 1). ${ }^{5}$

Before the municipal reform, the Aarhus University Prescription Database received and merged prescription data from Aarhus, North Jutland, Ringkjøbing, and Viborg counties. Because counties started contributing at different times, they differ with respect to the earliest availability of

Table I. The Danish regions after the 2007 municipal reform and corresponding former counties

\begin{tabular}{llll}
\hline Region (Danish name) & Population in 2009 & Former counties included in the two & Coverage since \\
& & regions & \\
\hline North Denmark Region (Region Nordjylland) & 580515 & Aarhus (one municipality) & 1996 \\
www.rn.dk & & North Jutland & $1989^{\mathrm{a}}$ \\
& & Viborg (five municipalities) & 1998 \\
Central Denmark Region (Region Midtjylland) & 1247732 & Aarhus (all but one municipalities) & 1996 \\
www.regionmidtjylland.dk & & Ringkjøbing & 1998 \\
& & Vejle (seven municipalities ${ }^{\mathrm{b}}$ ) & 2007 \\
& & Viborg (I2 municipalities) & 1998
\end{tabular}

Data sourced from www.regioner.dk

Notes: ${ }^{a}$ Complete coverage since February 1992; ' $A$ nnexed to the Central Denmark Region as a result of the 2007 municipal reform and are therefore represented in the regions' prescription database from 2007 onwards. 


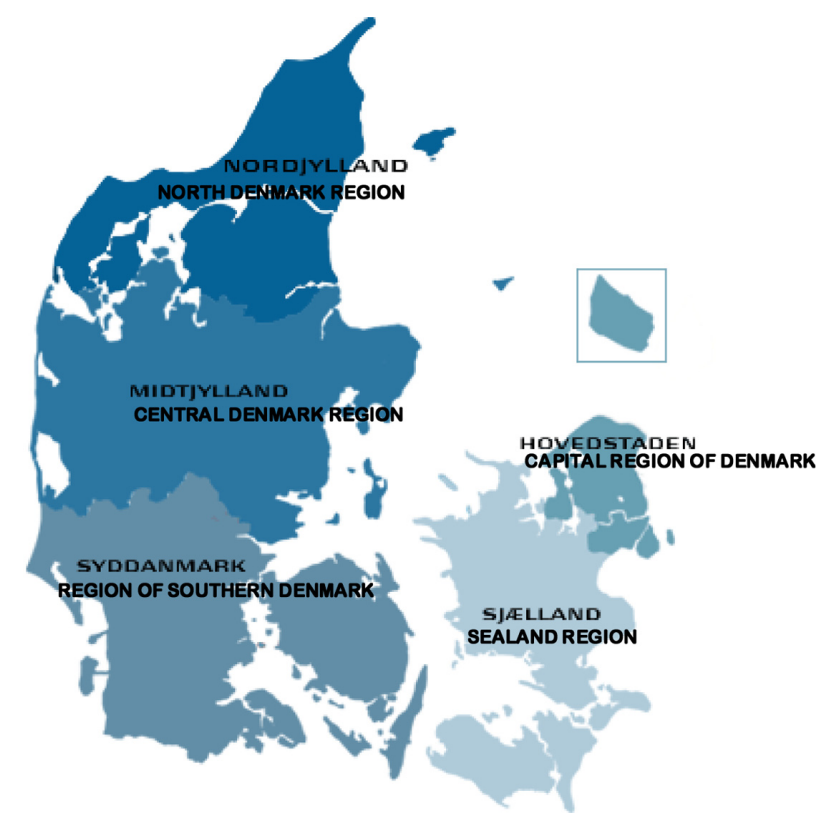

Figure I. The five regions of Denmark formed by the 2007 municipal reform (source: www.fm.dk). ${ }^{\mathrm{a}}$

Note: ${ }^{a}$ English names are given according to Danish Regions. ${ }^{5}$

the data. Data from the former North Jutland county are available since $1992,{ }^{6}$ from the former Aarhus county since 1996, and from the former Viborg and Ringkjøbing counties since 1998. After the municipal reform, the Aarhus University Prescription Database has been merging prescription data from the community pharmacies of the Central Denmark Region and the North Denmark Region.

\section{Data flow}

Ambulatory patients redeem prescriptions at community pharmacies, which electronically transmit dispensation data to the regional subdivisions of the National Health Service for reimbursement. Prescription reimbursement records must be de-identified within two months of sale. ${ }^{2}$ In order to enable individual-level linkage of prescription data to other medical databases, patient records need to remain identifiable. According to an agreement with Aarhus University, the National Health Service subdivisions of the Central Denmark Region and the North Denmark Region transfer individually identifiable dispensation data collected from the community pharmacies to the Department of Clinical Epidemiology at Aarhus University Hospital. The transfer is conducted using a password-protected encrypted connection, and the data are kept on a secure server. Data protection is further discussed below. The dispensation data are also reported to the Registry of Medicinal Products Statistics. ${ }^{1}$

\section{Variables}

One drug dispensation represents the unit of observation in the Aarhus University Prescription Database. Each line of record contains the following variables:

1. Patient's identifier (the so-called CPR number), which is a unique 10-digit numeric code assigned at birth or immigration by Denmark's Central Personal Registry. The first six digits of the CPR number correspond to the day, month, and year of birth, and the last digit encodes sex (odd digits for male; even digits for female). ${ }^{12}$ Prescriptions for children younger than 16 years were registered under the CPR numbers of their parents until April 1, 1996 and under the children's own CPR numbers thereafter;

2. Date of sale, which, in combination with the CPR number, enables calculation of the patient's age at dispensation;

3. Type of drug, which is coded according to the anatomical therapeutic chemical (ATC) classification, ${ }^{13}$

4. Universal product number (Varenummer), which encodes medication name, strength, pack size, dose units (eg, mg or $\mathrm{mL}$ ), defined daily dose (DDD), and manufacturer;

5. Provider code, which corresponds to a clinic, a practice, or a single physician. The provider code enables identification of the prescriber's specialty, name, and address, and in case of single practitioners, their age and sex.

\section{What is registered in the Aarhus University Prescription Database?}

Aarhus University Prescription Database records prescription medications that receive general or conditional reimbursement dispensed at the community pharmacies of the Central Denmark Region and the North Denmark Region. In 2009, 14.9 million dispensations were reported to the database. Table 2 and Figure 2 show the distribution of these dispensations by the major ATC classification group. Dispensations in group C (cardiovascular system) account for more than one-quarter of all dispensations, followed by dispensations in group $\mathrm{N}$ (nervous system), which account for more than one-fifth (Figure 2).

Thirty ATC codes account for half of all dispensations. The five most frequently dispensed medications are simvastatin (ATC code C10AA01), acetylsalicylic acid (ASA, B01AC06), paracetamol (N02BE01), metoprolol (C07AB02), and bendroflumethiazide (C03AB01) (Table 3).

The distribution of dispensations reflects the extent of byprescription use of ASA and paracetamol, which can be sold over the counter. ASA is reimbursed (and therefore recorded) if prescribed for specific indications, including primary and secondary prophylaxis of cardiovascular diseases. ${ }^{10}$ 
Table 2 Distribution of prescribed medicine recorded in the Aarhus University Prescription Database according to the 14 main ATC anatomic groups (2009)

\begin{tabular}{|c|c|c|c|}
\hline \multicolumn{2}{|c|}{$\begin{array}{l}\text { Anatomical main ATC } \\
\text { group, alphabetically }\end{array}$} & \multirow{2}{*}{$\begin{array}{l}\text { Number } \\
\text { I,580,837 }\end{array}$} & \multirow{2}{*}{$\begin{array}{l}\text { Percent } \\
10.61\end{array}$} \\
\hline A & $\begin{array}{l}\text { Alimentary tract } \\
\text { and metabolism }\end{array}$ & & \\
\hline B & $\begin{array}{l}\text { Blood and blood } \\
\text { forming organs }\end{array}$ & 972,851 & 6.53 \\
\hline C & $\begin{array}{l}\text { Cardiovascular } \\
\text { system }\end{array}$ & $3,902,845$ & 26.19 \\
\hline $\mathrm{D}$ & Dermatologicals & 416,072 & 2.79 \\
\hline G & $\begin{array}{l}\text { Genito-urinary system } \\
\text { and sex hormones }\end{array}$ & 437,840 & 2.94 \\
\hline $\mathrm{H}$ & $\begin{array}{l}\text { Systemic hormonal preparations, } \\
\text { excluding sex hormones and insulins }\end{array}$ & 402,689 & 2.70 \\
\hline J & Anti-infectives for systemic use & $|, 024,33|$ & 6.87 \\
\hline $\mathrm{L}$ & $\begin{array}{l}\text { Antineoplastic and } \\
\text { immunomodulating agents }\end{array}$ & 38,065 & 0.26 \\
\hline M & Musculoskeletal system & 887,667 & 5.96 \\
\hline $\mathrm{N}$ & Nervous system & $3,420,504$ & 22.96 \\
\hline$P$ & $\begin{array}{l}\text { Antiparasitic products, } \\
\text { insecticides, and repellents }\end{array}$ & 79,434 & 0.53 \\
\hline $\mathrm{R}$ & Respiratory system & $\mathrm{I}, 345,013$ & 9.03 \\
\hline$S$ & Sensory organs & 384,721 & 2.58 \\
\hline V & Various & 7,277 & 0.05 \\
\hline To & & $14,900,146$ & 100 \\
\hline
\end{tabular}

Abbreviations: ATC, anatomical therapeutic chemical.

Therefore, prescriptions for ASA recorded in the Aarhus University Prescription Database are expected to originate primarily from persons older than 55 years, or those with increased risk of cardiovascular morbidity. Paracetamol is reimbursable if prescribed for chronic pain. ${ }^{10}$ An estimated $11 \%$ of ASA and $80 \%$ of paracetamol packages prescribed in the primary sector are not reimbursed ${ }^{8}$ and therefore not recorded in the Aarhus University Prescription Database. Thus, for conditionally reimbursed medications, the proportion of dispensations recorded in the Aarhus University Prescription Database varies by pharmaceutical. The Internetbased database www.medstat.dk provides on-demand statistics (in Danish) on annual sales of pharmaceuticals with and without reimbursement in all sectors of health care. The aggregate statistics are available for each medication sold in Denmark and can be defined in packages or in daily doses. Using these data, degree of underascertainment of medication use due to lack of reimbursement can be estimated on a case-by-case basis.

\section{What is not registered}

The Aarhus University Prescription Database does not contain data on drugs that do not receive general or con- ditional reimbursement or drugs dispensed outside the community pharmacies of the two regions. The non-reimbursable medications include, for example, oral contraceptives and OTC medications (unless prescribed for chronic conditions, as discussed above). Reimbursed medications dispensed outside community pharmacies include medications dispensed directly to patients in hospitals or outpatient clinics. These include, for example, outpatient anti-neoplastic treatments, antiretroviral treatments for patients with human immunodeficiency virus infection, or substitution therapy for substance abusers. ${ }^{14}$ For drug-specific information regarding reimbursement rules ${ }^{9,10}$ and distribution of pharmaceutical sales according to reimbursement status and health care sector, ${ }^{8}$ the readers are referred to the relevant publications by the Danish Medicines Agency that are freely available on the Internet, the latter publication also in English. ${ }^{8}$

\section{Quality of data}

Pharmacies use bar code scanning to enter drug information into their database, making drug-related data entry errors highly unlikely. Potential dispensation of a wrong drug to a patient cannot be detected by examining the electronic data, but the frequency of such occasions is assumed to be negligible to meaningfully affect most study results. For the population of the two regions, dispensation records of reimbursed medications from community pharmacies, which are reported to the Aarhus University Prescription Database, are expected to

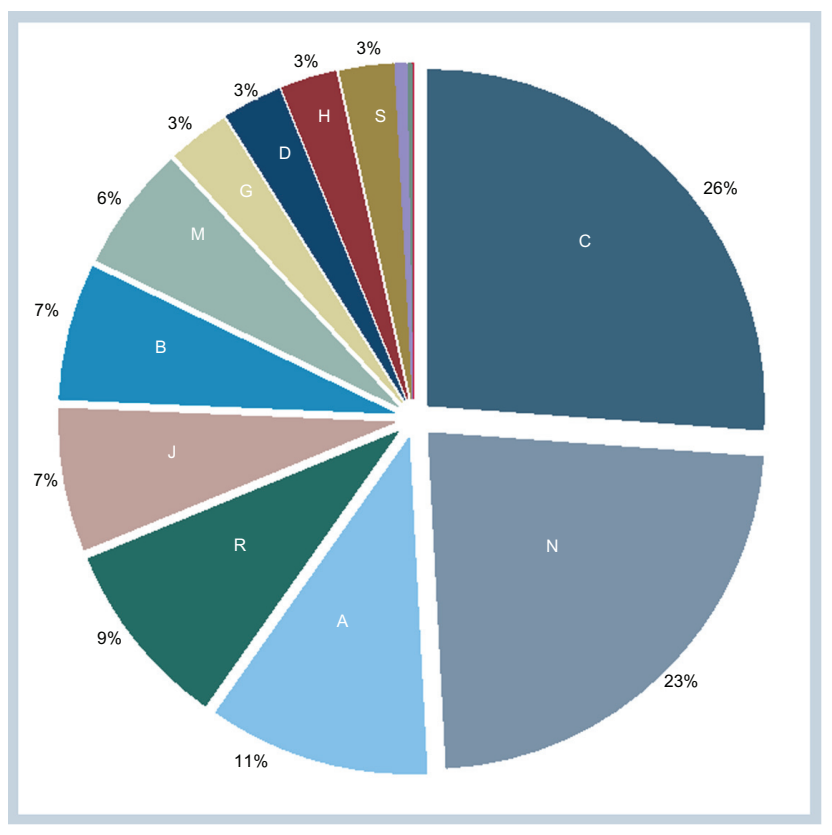

Figure 2. Percentage of dispensations recorded in the Regional Prescriptions Databases of the North Denmark Region and Central Denmark Region by anatomical therapeutic chemical group (2009). 
Table 3 ATC codes of the 30 most frequently dispensed prescription medications in 2009. These account for half of all dispensations recorded in the Aarhus University Prescription Database in 2009

\begin{tabular}{|c|c|c|c|c|c|c|}
\hline \multirow[t]{2}{*}{ Rank } & \multirow[t]{2}{*}{ ATC code } & \multirow[t]{2}{*}{ Generic name } & \multirow[t]{2}{*}{ Therapeutic group } & \multicolumn{3}{|c|}{ Dispensations } \\
\hline & & & & Number & Percent & Cumulative percent \\
\hline $\mathrm{I}$ & CIOAAOI & Simvastatin & Lipid modifying agents & 586,994 & 3.94 & 3.94 \\
\hline 2 & $\mathrm{~B} 0 \mathrm{IAC} 06$ & Acetylsalicylic acid & Platelet aggregation inhibitors & 575,459 & 3.86 & 7.80 \\
\hline 3 & N02BE0I & Paracetamol & Analgesics & 561,960 & 3.77 & $\mathrm{II} .57$ \\
\hline 4 & C07AB02 & Metoprolol & Beta-blocking agents & 397,647 & 2.67 & 14.24 \\
\hline 5 & С03АВ0I & $\begin{array}{l}\text { Bendroflumethiazide } \\
\text { and potassium }\end{array}$ & Diuretics & 373,883 & 2.51 & 16.75 \\
\hline 6 & N02AX02 & Tramadol & Analgesics & 373,566 & 2.51 & 19.26 \\
\hline 7 & MOIAEOI & Ibuprofen & $\begin{array}{l}\text { Anti-inflammatory and } \\
\text { antirheumatic products }\end{array}$ & 351,022 & 2.36 & 21.61 \\
\hline 8 & J0ICE02 & Phenoxymethylpenicillin & Antibacterials for systemic use & 342,875 & 2.30 & 23.92 \\
\hline 9 & CO3CAOI & Furosemide & Diuretics & 337,188 & 2.26 & 26.18 \\
\hline 10 & C08CAOI & Amlodipine & Calcium channel blockers & 325,525 & 2.18 & 28.36 \\
\hline II & N06AB04 & Citalopram & Psychoanaleptics & 308,399 & 2.07 & 30.43 \\
\hline 12 & $\mathrm{~A} \mid 2 \mathrm{BAOI}$ & Potassium chloride & Mineral supplements & 302,868 & 2.03 & 32.47 \\
\hline 13 & A $10 \mathrm{BA} 02$ & Metformin & Drugs used in diabetes & 232,332 & 1.56 & 34.02 \\
\hline 14 & C09AA02 & Enalapril & $\begin{array}{l}\text { Agents acting on the } \\
\text { renin-angiotensin system }\end{array}$ & 206,163 & 1.38 & 35.41 \\
\hline 15 & C09AA05 & Ramipri & & $|99,66|$ & 1.34 & 36.75 \\
\hline 16 & H03AA0I & Levothyroxine sodium & Thyroid therapy & 176,487 & 1.18 & 37.93 \\
\hline 17 & $\mathrm{~A} 02 \mathrm{BC} 03$ & Lansoprazole & Drugs for acid-related disorders & $17 \mid, 094$ & 1.15 & 39.08 \\
\hline 18 & N02AA05 & Oxycodone & Analgesics & 154,468 & 1.04 & 40.12 \\
\hline 19 & G03CA03 & Estradiol & Sex hormones & 150,859 & 1.01 & 41.13 \\
\hline 20 & R03AC02 & Salbutamol & $\begin{array}{l}\text { Drugs for obstructive airway } \\
\text { diseases }\end{array}$ & 138,253 & 0.93 & 42.06 \\
\hline 21 & $\mathrm{~A} 02 \mathrm{BC} 05$ & Esomeprazole & Drugs for acid-related disorders & 134,029 & 0.90 & 42.96 \\
\hline 22 & N06AXII & Mirtazapine & Psychoanaleptics & 129,964 & 0.87 & 43.83 \\
\hline 23 & B0IAA03 & Warfarin & Antithrombotic agents & 128,336 & 0.86 & 44.69 \\
\hline 24 & $\mathrm{~A} 02 \mathrm{BC} 0 \mathrm{I}$ & Omeprazole & Drugs for acid-related disorders & 120,269 & 0.81 & 45.50 \\
\hline 25 & N06ABIO & Escitalopram & Psychoanaleptics & 119,383 & 0.80 & 46.30 \\
\hline 26 & B0IAC07 & Dipyridamole & Antithrombotic agents & 119,024 & 0.80 & 47.10 \\
\hline 27 & R03AK06 & Salmeterol & $\begin{array}{l}\text { Drugs for obstructive airway } \\
\text { diseases }\end{array}$ & 117,433 & 0.79 & 47.89 \\
\hline 28 & R03BA02 & Budesonide & $\begin{array}{l}\text { Drugs for obstructive airway } \\
\text { diseases }\end{array}$ & 115,090 & 0.77 & 48.66 \\
\hline 29 & R03BB04 & Tiotropium bromide & $\begin{array}{l}\text { Drugs for obstructive airway } \\
\text { diseases }\end{array}$ & 113,320 & 0.76 & 49.42 \\
\hline 30 & M0IAX05 & Glucosamine & $\begin{array}{l}\text { Anti-inflammatory and } \\
\text { antirheumatic products }\end{array}$ & 108,622 & 0.73 & 50.15 \\
\hline
\end{tabular}

Abbreviation: ATC, anatomical therapeutic chemical.

be the same as records reported to the Registry of Medicinal Products Statistics. A cross-tabulation, at our department, of records with available data from both sources confirmed this expectation (unpublished data).

An estimated completeness of the Aarhus University Prescription Database is $96 \%$, based on cross-tabulation of insulin prescriptions with hospitalization records of diabetes mellitus in the former North Jutland county. ${ }^{4}$ However, completeness may vary by drug type. Furthermore, although dispensation record represents patients with primary adherence (those who purchase medications), it reflects neither the fact nor the exact timing of the actual medication intake.

\section{Record linkage and use of data in clinical research}

Thanks to patient-identifiable data in the Aarhus University Prescription Database, it is technically easy to link it to all other Danish registries, both nationwide and regional, using the CPR number. Because Denmark's registries are numerous and far-reaching even by the standards of Nordic countries, ${ }^{15}$ such linkage opens many possibilities for epidemiologic and interdisciplinary research. Linkage can be done, for example, to migration and vital status data in the Civil Registration System, ${ }^{12}$ hospitalization records in the Danish National Patient Registry, cancer diagnoses in the Danish Cancer Registry, 
or birth records in the Danish Medical Birth Registry. ${ }^{16}$ Linkage to the birth records is a valuable resource for studies of medication safety in pregnancy. Birth records contain both maternal and paternal CPR numbers of live- or still-born babies, allowing linkage of prescription and hospital records of parents and children. Examples of studies involving linkage to different data sources are given below. Even unlinked dispensation data can provide a wealth of information. Because each dispensation is identified by CPR number, it is possible to study patterns of drug utilization by patient age and sex and to reconstruct individual dispensation trajectories over time. The availability of prescription data since the mid-1990s enables the conduct of intergenerational studies. Besides Denmark, Finland is the only other Nordic country in which this is possible, because of the availability of prescription data since the 1990s, eg, parental use of medication before conception or birth can be examined for today's young adults. ${ }^{1}$

\section{Data access}

The Danish Act on Processing of Personal Data (Persondataloven) provides the legal basis for the ability of public institutions, including universities, to retain person-identifiable health data for research purposes. ${ }^{17}$ In order to access the data from the Aarhus University Prescription Database, researchers may apply to the Department of Clinical Epidemiology, at Aarhus University Hospital (www.kea.au.dk). Furthermore, use of any health data requires project-specific permission from the Data Protection Agency (Datatilsynet, www. datatilsynet.dk), and often additional permission for linkage from the National Board of Health (Sundhedsstyrelsen, www.sst.dk).

\section{Examples of studies conducted with data from the Aarhus University Prescription Database}

Reports of studies based on data from the Aarhus University Prescription Database have been published in several major international peer-reviewed journals and include both safety investigations and epidemiologic studies that use prescription record as a proxy measure of disease. A non-exhaustive list of examples includes investigations among pregnant women based on linkage to birth registry, including safety of non-steroidal anti-inflammatory drugs (NSAIDs), ${ }^{18}$ loratadine,${ }^{19}$ fluconazole,${ }^{20}$ selective serotonin reuptake inhibitors (SSRIs), ${ }^{21}$ and clomifene. ${ }^{22}$ Nørgaard et al used linkage with hospitalization records to investigate risk of miscarriage among pregnant users of pivmecillinam, while using data on the women's dispensation of anti-epileptic and anti-diabetic medications to control potential confounding by epilepsy and diabetes. ${ }^{23}$ Likewise, by linkage to hospitalization records, Johnsen et al examined the risk of myocardial infarction among users of several NSAIDs, ${ }^{24}$ Fryzek et al studied cancer risk among women using antihypertensive medications, ${ }^{25}$ Nørgaard et al used prescriptions for SSRIs as a marker of depression in a study of acute pancreatitis, ${ }^{26}$ and Lash et al and Cronin-Fenton et al studied the role of tamoxifen and SSRIs in preventing the recurrence of breast cancer. ${ }^{27-29}$ Finally, several investigations demonstrated socioeconomic differences in drug utilization by linking prescription dispensation records from Aarhus University Prescription Database to individual-level socioeconomic indicators. ${ }^{30-33}$

\section{Conclusion}

Routinely recorded person-identifiable prescription data have many uses, including post-approval research or etiologic studies. The Aarhus University Prescription Database contains, with few exceptions, dispensation data on reimbursed medicine for the entire population of two Danish geographic regions representing one-third of the country's population. The data are accessible for research and are linkable to all other Danish databases and registries. The main drawbacks of the Aarhus University Prescription Database are a lack of nationwide coverage and the absence of data of certain medication types. At the same time, a vast majority of prescription dispensations are routinely recorded, with more than 15 years' worth of follow-up data accumulated to date. Thus, the Aarhus University Prescription Database represents a valuable research tool for many epidemiologic applications.

\section{Disclosure}

The authors report no conflict of interest for this work.

\section{References}

1. Furu K, Wettermark B, Andersen M, Martikainen JE, Almarsdottir AB, Sørensen HT. The Nordic countries as a cohort for pharmacoepidemiological research. Basic Clin Pharmacol Toxicol. 2010;106(2):86-94.

2. Hallas J. Conducting pharmacoepidemiologic research in Denmark. Pharmacoepidemiol Drug Saf. 2001;10(7):619-623.

3. Frank L. Epidemiology. The epidemiologist's dream: Denmark. Science. 2003;301(5630):163.

4. Nielsen GL, Sørensen HT, Pedersen AB, Sabroe S. Analyses of data quality in registries concerning diabetes mellitus - a comparison between a population based hospital discharge and an insulin prescription registry. J Med Syst. 1996;20(1):1-10.

5. Danish Regions. The Danish regions in brief. 2008. Accessed 2010 Oct 6. Available from: http://www.regioner.dk/In $\% 20$ English/Publications $\% 20$ and $\% 20$ Policy\%20Papers/The\%20Regions\%20in\%20Denmark.aspx

6. Nielsen GL, Sørensen HT, Zhou W. The Pharmacoepidemiologic Prescription Database of North Jutland - a valid tool in pharmacoepidemiological research. Int J Risk Safety Med. 1997;10:203-205. 
7. Ministry of Interior and Health. Health Care in Denmark 2008. Accessed 2010 May 17. Available from: http://www.sum.dk/Aktuelt/ Publikationer/Publikationer/UK_Healthcare_in_DK.aspx

8. Danish Medicines Agency. Medicinal Products Statistics. Denmark, 2004-2008. Total sales. Accessed 2010 Oct 6. Available from: http://www.dkma.dk/db/filarkiv/7004/Samlet $\% 20$ salg\%20af\% 201lgemidler\%202004-2008.pdf

9. Danish Medicines Agency. Reimbursement. Accessed 2010 Oct 6. Available from: http://www.dkma.dk/1024/visUKLSArtikel asp?artikelID $=1469$

10. Danish Medicines Agency. Medicines eligible for reimbursement [in Danish: Skrivelse om tilskudsberettigede lægemidler]. Accessed 2010 Oct 6. Available from: http://www.laegemiddelstyrelsen.dk/db/ filarkiv/5195/tilskudsberettigede.pdf

11. Danish Medicines Agency. Reassessment of reimbursement status for medicinal products. Accessed 2010 Oct 6 . Available from: http://www. $\mathrm{dkma.dk} / 1024 / \mathrm{vis} U K L S A r t i k e l . a s p ?$ artikelID $=6301$

12. Pedersen CB, Gotzsche H, Moller JO, Mortensen PB. The Danish Civil Registration System. A cohort of eight million persons. Dan Med Bull. 2006;53(4):441-449.

13. WHO Collaborating Centre for Drug Statistics Methodology Norwegian Institute of Public Health. WHO ATC/DDD Index. Accessed 2010 Oct 6 Available from: http://www.whocc.no/atc_ddd_index/

14. Kildemoes HW, Sorensen HT, Hallas J. The Danish National Prescription Registry (unpublished work).

15. Frank L. Epidemiology. When an entire country is a cohort. Science. 2000;287(5462):2398-2399.

16. Knudsen LB, Olsen J. The Danish Medical Birth Registry. Dan Med Bull. 1998;45(3):320-323.

17. Persondataloven (Data Protection Act). Accessed 2010 Oct 6 . Available from: http://www.datatilsynet.dk/lovgivning/persondataloven/English version. Accessed 2010 Oct 6 . Available from: http://www.datatilsynet. $\mathrm{dk} /$ english/the-act-on-processing-of-personal-data/

18. Nielsen GL, Sorensen HT, Larsen H, Pedersen L. Risk of adverse birth outcome and miscarriage in pregnant users of non-steroidal anti-inflammatory drugs: population based observational study and case-control study. BMJ. 2001;322(7281):266-270.

19. Pedersen L, Norgaard M, Rothman KJ, Sorensen HT. Loratadine during pregnancy and hypospadias. Epidemiology. 2008;19(2):359-360.

20. Norgaard M, Pedersen L, Gislum M, et al. Maternal use of fluconazole and risk of congenital malformations: a Danish population-based cohort study. J Antimicrob Chemother. 2008;62(1):172-176.

21. Wogelius P, Norgaard M, Gislum M, et al. Maternal use of selective serotonin reuptake inhibitors and risk of congenital malformations. Epidemiology. 2006;17(6):701-704.
22. Sorensen HT, Pedersen L, Skriver MV, Norgaard M, Norgard B, Hatch EE. Use of clomifene during early pregnancy and risk of hypospadias: population based case-control study. BMJ. 2005;330(7483): 126-127.

23. Norgaard M, Skriver MV, Sorensen HT, Schonheyder HC, Pedersen L. Risk of miscarriage for pregnant users of pivmecillinam: a populationbased case-control study. APMIS. 2008;116(4):278-283.

24. Johnsen SP, Larsson H, Tarone RE, et al. Risk of hospitalization for myocardial infarction among users of rofecoxib, celecoxib, and other NSAIDs: a population-based case-control study. Arch Intern Med. 2005; 165(9):978-984.

25. Fryzek JP, Poulsen AH, Lipworth L, et al. A cohort study of antihypertensive medication use and breast cancer among Danish women. Breast Cancer Res Treat. 2006;97(3):231-236.

26. Norgaard M, Jacobsen J, Gasse C, Pedersen L, Mortensen PB, Sorensen HT. Selective serotonin reuptake inhibitors and risk of acute pancreatitis: a population-based case-control study. J Clin Psychopharmacol. 2007;27(3):259-262.

27. Lash TL, Pedersen L, Cronin-Fenton D, et al. Tamoxifen's protection against breast cancer recurrence is not reduced by concurrent use of the SSRI citalopram. Br J Cancer. 2008;99(4):616-621.

28. Cronin-Fenton D, Lash TL, Sorensen HT. Selective serotonin reuptake inhibitors and adjuvant tamoxifen therapy: risk of breast cancer recurrence and mortality. Future Oncol. 2010;6(6):877-880.

29. Lash TL, Cronin-Fenton D, Ahern TP, et al. Breast cancer recurrence risk related to concurrent use of SSRI antidepressants and tamoxifen. Acta Oncol. 2010;49(3):305-312.

30. Thrane N, Olesen C, Schonheyder HC, Sorensen HT. Socioeconomic factors and prescription of antibiotics in 0- to 2-year-old Danish children. J Antimicrob Chemother. 2003;51(3):683-689.

31. Thomsen RW, Johnsen SP, Olesen AV, et al. Socioeconomic gradient in use of statins among Danish patients: population-based cross-sectional study. Br J Clin Pharmacol. 2005;60(5):534-542.

32. Olesen C, Thrane N, Henriksen TB, Ehrenstein V, Olsen J. Associations between socio-economic factors and the use of prescription medication during pregnancy: a population-based study among 19,874 Danish women. Eur J Clin Pharmacol. 2006;62(7):547-553.

33. Mortensen JT, Olesen AV, Boggild H, Olsen J, Westergard-Nielsen NC. Socioeconomic correlates of drug use based on prescription data: a population-based cross-sectional register study in Denmark 1999. Dan Med Bull. 2007;54(1):62-66.
Clinical Epidemiology

\section{Publish your work in this journal}

Clinical Epidemiology is an international, peer-reviewed, open access journal focusing on disease and drug epidemiology, identification of risk factors and screening procedures to develop optimal preventative initiatives and programs. Specific topics include: diagnosis, prognosis, treatment, screening, prevention, risk factor modification, systematic

\section{Dovepress}

reviews, risk \& safety of medical interventions, epidemiology \& biostatical methods, evaluation of guidelines, translational medicine, health policies \& economic evaluations. The manuscript management system is completely online and includes a very quick and fair peer-review system, which is all easy to use. 